\title{
Simulation in Nurse Teacher Education - Preservice Teachers' Experiences of Basic Structures and Utilization of Simulation-Based Learning
}

\author{
Terhi Saaranen ${ }^{*, 1}$, Anne Vaajoki ${ }^{1}$, Marjorita Sormunen ${ }^{1}$, Heikki Paakkonen ${ }^{2}$ and Kerttu Tossavainen ${ }^{1}$ \\ ${ }^{I}$ University of Eastern Finland, Faculty of Health Sciences, Kuopio Campus, Department of Nursing Science, \\ P.O.B 1627, 70211 Kuopio, Finland \\ ${ }^{2}$ Kuopio University Hospital, Clinical Support Services, Prehospital Emergency Care, Emergency Department and \\ Intensive Care, P.O.B 100, 70029 KYS, Kuopio, Finland
}

\begin{abstract}
Using simulation as a method of teaching and learning has become more prevalent on both the national and international levels. We developed and implemented an educational simulation-learning event for second-year nurse teacher students of the University of Eastern Finland, which is carried out every year. This study aims to explore how the students considered their abilities to master all the stages of a simulation exercise, and what the students felt they had learned from the learning event. The data were collected using a questionnaire with both quantitative and qualitative components. The quantitative data were analyzed with descriptive statistical methods and the qualitative data using inductive content analysis. The majority of the students stated that they were able to distinguish between the stages of a simulation-learning event. However, the actual simulation-specific concepts were not familiar to all the students while describing the stages. More than two-thirds of the students were confident in their ability to use their own skills to plan and execute a simulation-learning event in a health care setting after participating in the simulation event. A majority of the students believed that the simulation event increased their knowledge and skills, especially in terms of the use of simulation, the importance of the teacher' $s$ role, and teamwork. In regards to nursing and teaching practice, the remarkable role of the teachers in charge of planning and implementing a simulation event is worth noticing, as well as the exact use of adequate concepts to describe the phenomena related to simulation learning events.
\end{abstract}

Keywords: Nurse teacher, qualitative study, quantitative study, simulation.

\section{INTRODUCTION}

Using simulation as a teaching method in nursing and nurse education has become more prevalent on both the national and international levels $[1,2]$, and learning institutions in the field have adopted different simulation techniques to educate professionals in the area. Simulation teaching is particularly used in situations that would be difficult or even impossible to practice in genuine and natural environments. As a general concept, simulation mainly refers to constructing an artificial world in a simulated environment. In that case, simulation is an attempt to achieve a process in the real world whose educational goal is to produce comprehensive and experience-based learning $[3,4]$ in situations where practicing knowledge and skills must occur in absolute safety $[1,2,5]$.

There has been much research on the impact of simulation exercises from the point of view of nursing students in different educational levels regarding combining theoretical and practical knowledge [6,7] and collaborative relationships in clinical nursing situations (e.g., [8]). According to a study by Hope and colleagues (2011), students felt that the simulation learning method helped them

*Address correspondence to this author at the University of Eastern Finland, Faculty of Health Sciences, Kuopio Campus, Department of Nursing Science, P.O.B 1627, 70211 Kuopio, Finland; Tel: +358 500940 242;

E-mail: terhi.saaranen@uef.fi improve their problem solving, psychomotor, and technical skills. Simulations can also be used to practice communication, collaboration, and interaction skills that link to patient safety $[5,8]$, cognitive and skill-related abilities [6, 9], and decision-making skills and the ability to think critically, competencies that are linked to guidance and teaching $[5,10]$. Communication within and between multidisciplinary work groups, or the lack thereof, has been proven to be a significant factor in endangering patient safety $[11,12]$ and in decreasing the occupational well-being of workers. A study by Dillon et al. [8] evaluated the collaborative relationships between nurses and medical students before and after a high fidelity simulation. According to the study, the simulation exercise functioned well in developing collaboration, and promoted communication readiness, which increases patient safety. Up to $70 \%$ of errors leading to harmful events have been evaluated as being caused by human factors [13] and simulation has been described as a good teaching method for preventing these.

However, some doubts in using simulation for learning purposes have also been expressed. The expense of personnel and equipment [14], underutilization of these complex and technologically advanced systems in education $[15,16]$, faculty time and proficiency with simulation equipment [17], and the inappropriate identity construction of nursing students in the simulated setting [2] are among the 
most common disadvantages that have been associated with simulation as a learning method. Moreover, some students consider their role in simulation as a performer and being observed by others to be a stressful experience, and might even find that it causes anxiety [18-20].

There remains little research information from the viewpoint of those functioning in teaching and managerial positions [21], even though they must have basic competencies in simulation pedagogy, for instance, on how students learn with the simulation method. There is particularly a need for evidence-based research on the benefits and challenges of simulation teaching and learning in nurse teacher education, as the teachers in the field of health care that graduate from the training are the ones applying and using the simulation method in the future. Therefore, it is important to practice the basic facilities of simulation pedagogy and use the methods of simulation teaching and learning so that, in the future, they can utilize simulation learning and teaching in their work in clinical nursing, as well as in the context of an educational institution.

Future health care teachers must understand the benefits and challenges of the method and know how to apply the methods of simulation teaching and learning so that it will best meet the goals set for the field of health care. This article describes factors relating to the simulation studies of the second-year students in the nurse-teacher education program at the University of Eastern Finland (i.e., theoretical background and realization) and the self-assessments of their experiences (pilot study) after the simulation-learning day.

\section{Simulation Pedagogy and Simulation in the Nurse Teacher Education Program at the University of Eastern Finland}

There are several learning theories behind simulation learning and teaching, such as the realistic, socioconstructive, and experiential learning theories. Realistic simulation teaching highlights the reality of the material world and the responsibility of teachers to get learning constructions by learners to measure up to the known reality [22]. Social constructivism emphasizes, among other things, the active involvement of students. Previous positive research findings (e.g., [5, 23]) on simulation learning support both relative constructive and socio-constructive learning theories, as simulated group practice situations that mimic reality have been found to promote learning and the development of social skills, such as team skills and interactive competencies.

In addition, simulation learning can be strongly connected to Kolb's theory [24], where learning is associated with practical experiences and acquired knowledge, as a learner has skills to reflect his/her own activities, and she/he is motivated to develop themselves. A learning process can be divided into a cycle consisting of experiencing, reflecting, conceptualising, and experimenting-concrete to abstract and active experimentation to reflective observations [24]. The ultimate purpose of simulation teaching is that the learner can combine theoretical and practical knowledge [7]. This means that what has been learned can be used and can be applied in different situations and contexts, in which case transfer of information takes place. A teacher guiding simulation must plan the simulation-learning event so that it is possible to reach this transfer as perfectly as possible [1, 25].

It is also important to understand that individual learning styles can change the dynamics of the group, and the simulation instructors may have to change teaching strategies. Learning styles refer to the view that different people learn information in different ways and in different settings [26]. In a more detailed observation, a learning style refers to the way in which a learner begins to concentrate, process, acquire, and retain new information. This can include learning based on aural or visual observations, or learning through experiences, that is, how people's intentions are expressed through non-verbal communication (kinesthetic learning) [27]. However, based on previous literature, it would appear that there has been little, if any, research on the importance of students' different learning styles (auditory, visual, kinesthetic) and/or their connection to simulation learning and teaching.

Since 2009, simulation learning and teaching have been used in the Nurse Teacher Education of the University of Eastern Finland that has nursing science as a major subject. Simulation training goals range from technical skills to nontechnical skills. At the Department of Nursing Science, nontechnical skills are in focus: simulation pedagogy, individual's operation models, cooperation models, and communication (intrapersonal, interpersonal, and small group/team communication) behaviors. One of the goals of simulation is to enhance critical thinking and decisionmaking, and a further goal is to create preparedness by using simulation as a learning method.

Simulation in the Nurse Teacher Education is a smallgroup learning and teaching method that is interactive, realistic, problem-based, effective, and involves learning by doing and by motivating. Simulations allow teachers, nurse students, student peers, and student teams to observe, assess, and give feedback on nonverbal and verbal communication and behavior in a clinical-type setting. With the use of simulations, teachers can create scenarios and assess a student's critical thinking and behavior.

Simulation consists of three different phases: preparation for the simulation, actual practice, and debriefing. Preparation for the simulation includes an orientation and participant training [28] / introduction and simulator briefing [29], actual practice includes participation in the simulation [28] / scenarios [29], and the last phase is debriefing [28, 29]. At first, teachers present the goals of simulation. Case scenarios have been created beforehand, for example, cases, roles, situations, operational environments, and progress. Teachers and students agree on the situation and the simulation rules in advance to ensure a safe training environment for all participants. Students select the voluntary participants to act in a case scenario. The rest of the students are divided into two groups to observe the negative or positive points. Actual practice (case scenario) lasts about ten to fifteen minutes. The teachers control the situation during the scenario. After the real scenario, the students and teachers discuss the simulation situation. First, the actors describe what has happened in the scenario and what the roles were. Second, teachers point out selected and critical parts of the scenario. Students discuss, reflect, and 
evaluate what kind of behavior is worthwhile to continue or what should not to be continued in the future. Before closing the case, students and teachers assess what they have learned during the simulation-learning event.

This study is based on the experiences of second-year nurse teacher students during a simulation-learning day in a "real" case scenario situation in the simulation laboratory that is part of the course "Teaching Training in Nursing Education". The research was a pilot study conducted in the fall of 2011. Before partaking in the "real" case scenario situation, students learned about simulation pedagogy in theory in the second year course, "Didactics of Nursing Science".

In addition, students familiarize themselves with the simulation technology in the simulation laboratory in the course, "Teaching Technology in Health Education and Guidance" during their first year of studies, and in the third year, students study communication theory and apply different kinds of challenging interaction situations in the simulation laboratory in the course, "Challenging Situations in Speech Communication". All simulation cases are situations from nursing education practice, nursing practice, and leadership.

\section{MATERIALS AND METHODOLOGY}

The purpose of this study is to describe the experiences of second-year nurse teacher students, as evaluated by them, after an eight-hour simulation-learning event. The goal of this research is to produce information that can be utilized in the development of nurse teacher education.

The research questions are:

1. How did the nurse teacher students consider their abilities to describe, plan, and carry out the simulation-learning event?

2. What did the nurse teacher students feel that they learned from the simulation-learning event?

\section{Participants and Questionnaire}

Seventeen nurse teacher students participated in the study. On average, the students graduated with a master's degree in Health Sciences in 3-4 years, with Nursing Science as their major. The students participating in this study were in their second year of studies. A questionnaire was filled out after the simulation-learning event with the use of instrumentation that had been created for the evaluation of the simulation-learning event. The instrument included questions on background variables (multiple-choice, questions 1-5) and on students' experiences with simulation learning and the learning event (statements, 6-17). Statements 6-16 had students evaluate matters connected to simulation learning and the learning event by marking on a Visual Analogue Scale (VAS) how well each statement corresponded with their experience on simulation learning or the learning event $(0=$ not at all... 10=very well). Moreover, students wrote down reasons for the score they gave. Finally, there was an open-ended question (question 17) where students could explain in their own words anything else they would like to say about simulation learning or the simulation-learning event.

\section{Data Analyses}

The quantitative data were analyzed using the percentages (\%) and the number (n) of respondents as descriptive statistical methods. Boxplots were used to illustrate the distribution of responses. Furthermore, connections between the background variables (age, earlier experiences with simulation, learning style) were tested with the individual variables reported in this article, of which only the statistically significant connections will be discussed in the section on results. The Mann-Whitney u-test and the Kruskall-Wallis test were used as methods. Qualitative data were analyzed using inductive content analysis by research questions by classifying data both qualitatively and quantitatively [30]. Simplified expressions were formed based on original expressions, and these were then grouped into uniform groups based on their content. The groups were given names that described their content as well as possible. The results section also presents numbers (n) based on the qualitative data. These refer to the number of students who expressed given ideas in the subcategories.

\section{Validity and Reliability}

The results of the study cannot be generalized as the small sample size reduces the reliability of the study and the research was carried out in one organization during a single course [30]. Therefore, the fairly highly qualitative research results cannot be used to make any statements regarding the effects of simulation activities. On the other hand, all of the teacher students who participated in the course were interested in answering the questionnaire [30] and thus these results offer important information about the participants' experiences of the simulation.

The measurement tool was formulated for this pilot study by becoming acquainted with international studies on the simulation learning method. After the pilot study, some of the background variable questions in the questionnaire were clarified regarding their classifications (the second data were collected using the same measurement tool in the fall of 2012), but the measurement tool was found otherwise functional. The research data were gathered using ethically sustainable data acquisition methods [31]. The teacher students of health sciences were verbally informed of the voluntary and confidential nature of the study in the simulation-learning event. The data for this study has been handled confidentially and will be disposed of after the study has ended.

\section{RESULTS}

\section{Background}

Over half of the participants were between the ages of 36-50. Three students (18\%) had previous experience with simulation learning. Twelve $(71 \%)$ nurse teacher students reported their learning style as visual, three (18\%) as kinesthetic, and two (12\%) as auditory (Table 1).

\section{Experiences of Students in the Nurse Teacher Education on Describing, Planning, and Realizing a Simulation Learning Event}

One-third of students $(29 \%, n=5)$ reported that they were very good (evaluation over 8 on the VAS) at describing the 
Table 1. Background Variables of Students of Nurse Teacher Education $(\mathrm{N}=17)$

\begin{tabular}{|l|c|c|}
\hline Background Variables & n & $\%$ \\
\hline \hline Age & 7 & 41 \\
\hline$\leq 35$ & 9 & 53 \\
\hline $36-50$ & 1 & 6 \\
\hline$\geq 51$ & 3 & 18 \\
\hline Earlier Experiences of Simulation & 82 \\
\hline Yes & 14 & 100.0 \\
\hline No & 17 & 12 \\
\hline Total & \multicolumn{2}{|l|}{} \\
\hline Learning Style & 2 & 70 \\
\hline Auditive & 12 & 18 \\
\hline Visual & 3 & 100 \\
\hline Kinestetic & 17 & \\
\hline Total & &
\end{tabular}

different stages of simulation learning. The mean of all respondents was 7.93 on the VAS with a range of 4.8-10 (Fig. 1).

Nearly all students $(94 \%, n=16)$ described the stages of simulation learning in a section where they gave reasons for their choices, in which they were to describe the different stages in their own words. One of the students left both the
VAS statement and the reason for their choice unanswered. The section on reasons described the stages as follows:

“Planning/preparing, realization, evaluation”

"Explaining the case situation, sharing out roles, the simulation event itself with its directions, stopping the simulation, a round where all participants introduce their case and their role, looking at case points, going through positive things, going through negative things"

"Introduction - preparation: roles for all learners, scenario in the simulation event that is recorded in video, breaking down the event: debriefing = learning, ending: letting go of the simulation role"

A three-fold understanding of the stages of the simulation-learning event was apparent in all of the descriptions: 1) planning/preparing, 2) realization, and 3) evaluation.

More than one-third of the students $(35 \%, n=6)$ felt after the simulation-learning event that they are very good (evaluation of over 8 on the VAS scale) at planning $a$ simulation event in some area of nursing. The mean of all respondents was 7.26 on the VAS with a range of 4.9-9.3 (Fig. 2).

Slightly over two-thirds $(65 \%, \mathrm{n}=11)$ of the students described in the open-ended questions/reasons that they knew how to plan a simulation-learning event in some area of nursing after the simulation day had ended.

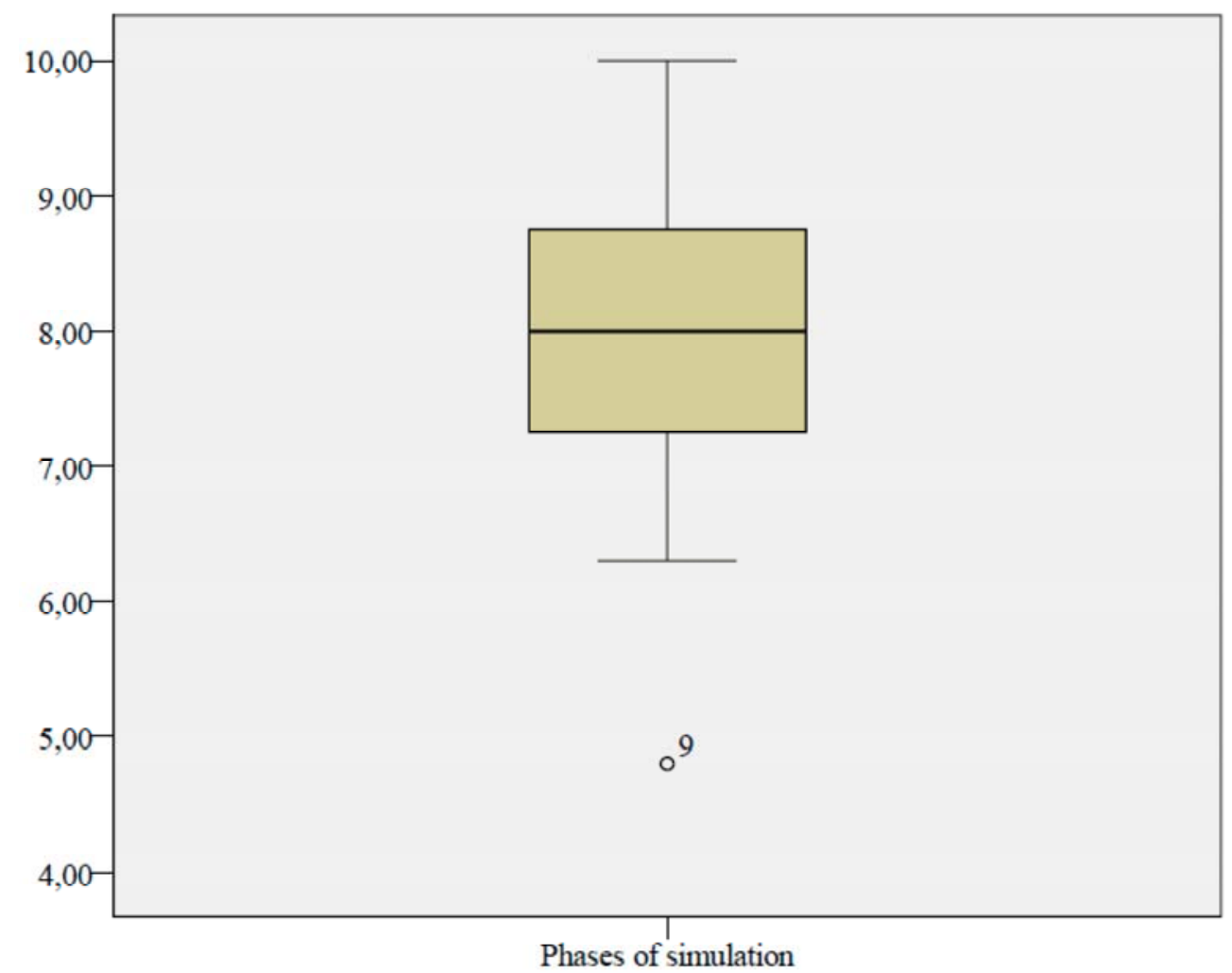

Fig. (1). Evaluation by students in the nurse teacher education on how well they could describe the stages of the simulation learning event after it had taken place $(\min 0 \ldots 10)$. 


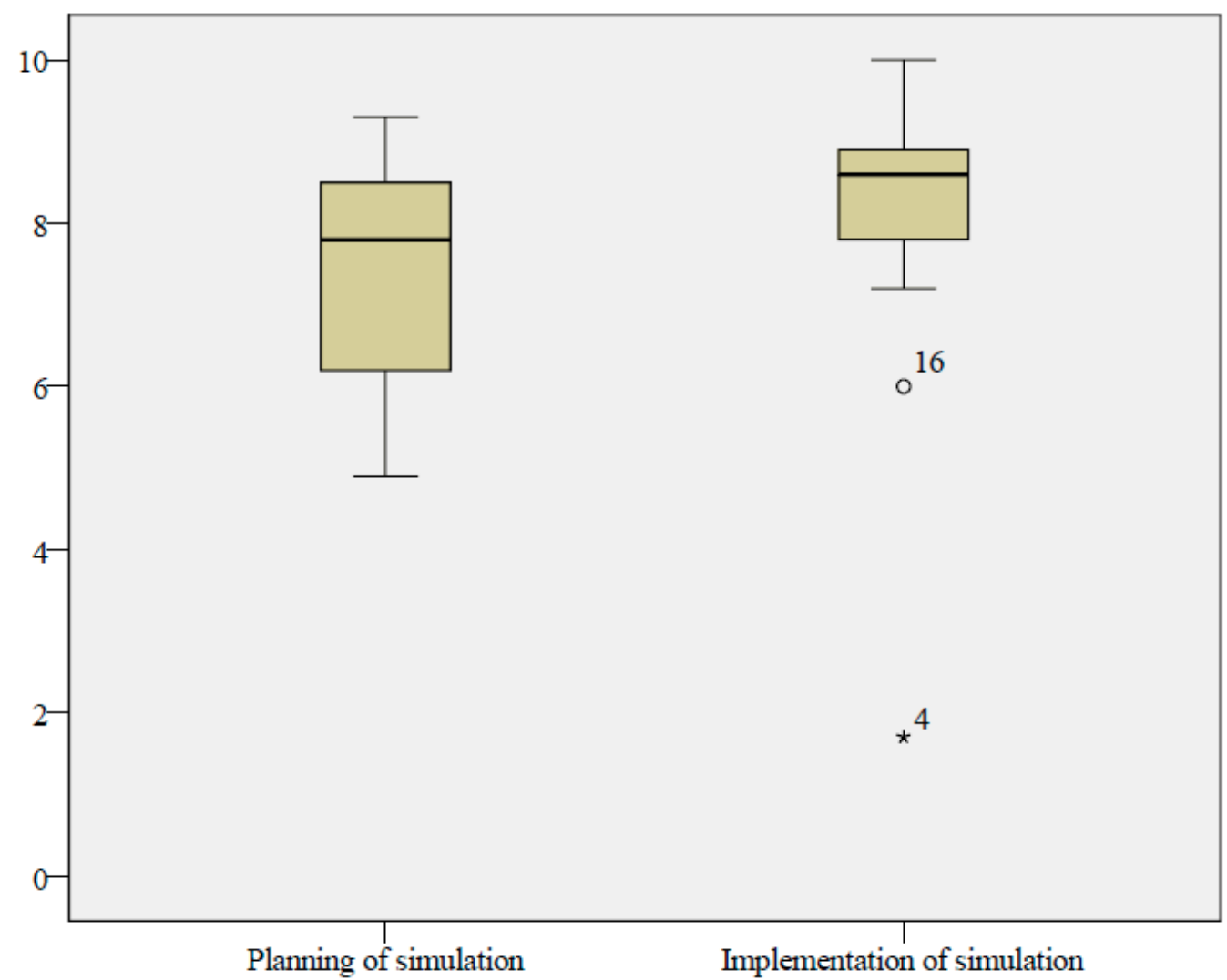

Fig. (2). Evaluation of students in nurse teacher education on their preparedness to plan and realize a simulation learning event (min 0 ...max 10).

"I know I can plan it, even though a good proficiency can be achieved also in this by repeating it many times and having several experiences"

"Maybe I will still in some parts have to rely on literature, but the basic principles are clear"

However, based on the open-ended responses, more than half $(59 \%, \mathrm{n}=10)$ of the students expressed that they would still need more practice on a general level or on their computational skills relating to the simulation event.

"Foundations have been built and interest has been aroused. More training will be needed"

"(I can) Plan, but the technical realization is a different matter"

"I could plan a case, but managing it as a whole is not possible yet. I'd need training. This was an introduction to the method"

More than half of the students $(59 \%, n=10)$ reported on the VAS that they primarily have very good knowledge (an evaluation of over 8 on the VAS) on how simulations are carried out in practice on certain areas of nursing after the simulation day. The mean of all respondents was 8.04 on the VAS scale with a range of 1.7-10 (Fig. 2). Out of the background variables (age, earlier experiences with simulation, learning style), age had the most statistically significant connection to the topic in question $(\mathrm{p}=0.018)$; the age group with participants 36-50 years old felt the most positive that they would be able to create a simulation in some area of nursing.

Moreover, more than two-thirds $(71 \%, \mathrm{n}=12)$ of students described in the open questions that they knew roughly how to carry out a simulation in practice.

"Actively following and taking part in two simulations has taught me the basic outlines of realizing a simulation”

"Basic outlines are ok, more practice before carrying it out”

\section{Perspectives to Simulation Learning - Learning Experiences of Students in Nurse Teacher Education on the Simulation Learning Event}

Over two-thirds of the students $(71 \%, \mathrm{n}=12)$ felt that the simulation-learning event promoted learning on the possibilities for using simulation very well (evaluation of over 8 on the VAS). The mean score of all respondents was 8.51 on the VAS with a range of 3.8-10 (Fig. 3).

The students of nurse teacher education expressed that the simulation learning event helped them learn about the versatility of learning methods $(n=6)$, the importance of the role of the teacher $(n=4)$, and the importance of an enthusiastic and safe group for learning $(n=2)$.

\section{"My view on the versatility of learning} methods changed”

"It gave me tools for using simulation as a teacher" 


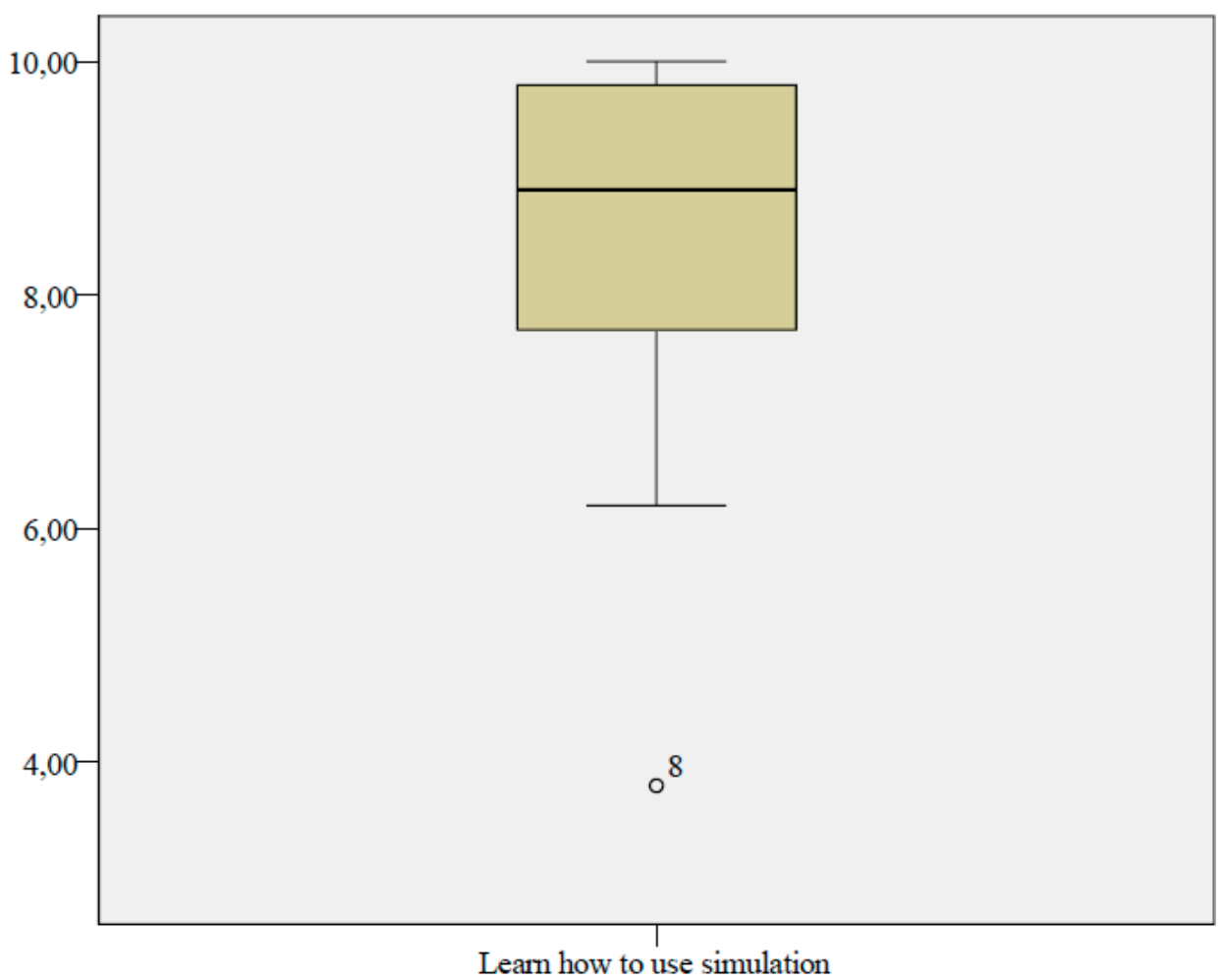

Fig. (3). Experiences of students of nurse teacher education on learning the possibilities for using simulation (min0....max 10).

\section{“A safe group promotes my learning”}

One-third of students felt that their knowledge about the whole simulation process increased $(\mathrm{n}=6)$ and the concrete situations were considered educational $(\mathrm{n}=6)$.

"The pedagogy was explained stage by stage and reasonably"

"There was no previous knowledge so it was a good introduction to the basics of simulation"

"Personal experience"

"You could participate in simulation learning in a concrete way"

Two More than half of the students $(59 \%, n=10)$ reported on the VAS that they primarily -thirds of students $(65 \%$, $\mathrm{n}=11$ ) reported that the feedback discussion session promoted their learning very well (evaluation score of over 8 on the VAS) in constructing a simulation learning event. The mean score of all respondents was 8.36 on the VAS with a range of 5.8-10 (Fig. 4).

Furthermore, nearly all of the students $(94 \%, n=16)$ wrote about the positive effect of the debriefing on their learning about constructing a simulation-learning event in the open questions.

"The feedback discussion was the best part; of course you think about benefits/harms when looking at the case activities, but the shared discussion opens up views that you would not think of yourself"

"The feedback made it possible to look at the situations in a complex way and ideas that were significant to the organizers also came up"

Nearly half $(47 \%, \mathrm{n}=8)$ of the students reported that the debriefing promoted their learning on the subject area of the scenario very well (evaluation score of over 8 on the VAS). The mean score of all respondents was 8.27 on the VAS with a range of 2.0-10 (Fig. 4).

In their arguments, five of the responses highlighted the fact that the scenario had brought up particularly new viewpoints of the subject area.

"Good points on how the situation could be otherwise dealt with"

"Many ideas came up from different viewpoints. Everyone got to, and had to, say something"

Approximately one-third $(29 \%, \mathrm{n}=5)$ of students reported that the debriefing did not cause them any anxiety (evaluation score of 0 on the VAS). The mean score of all respondents was 0.54 with a range of 0-2.3 (Fig. 5).

In their open reasons, five $(n=5)$ students expressed that the atmosphere was good, encouraging, and appropriate. Three $(n=3)$ students highlighted that the teacher's behavior had promoted learning.

"An encouraging atmosphere; opinions were not dismissed and no one was disrespected "

"Feedback was feedback, dialogic, permissive, non-judgmental, there was no finger pointing"

"The feedback discussion was constructive, it was done via roles. So it was not focused on you as a person" 


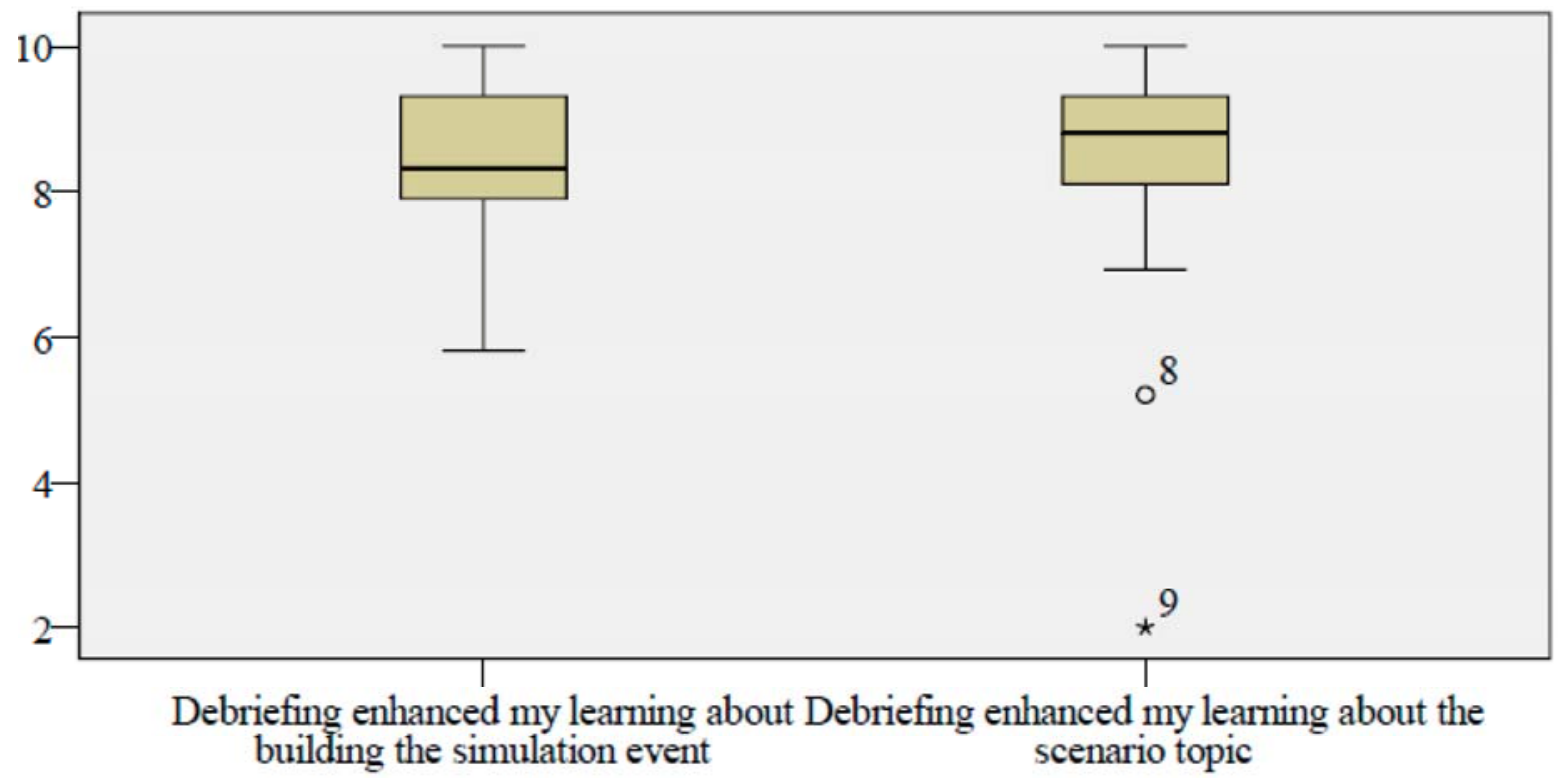

Fig. (4). The experiences of students of nurse teacher education on how the feedback discussion promoted their learning about constructing a simulation learning event and the subject area of the scenario (min $0 \ldots$ max 10$)$.

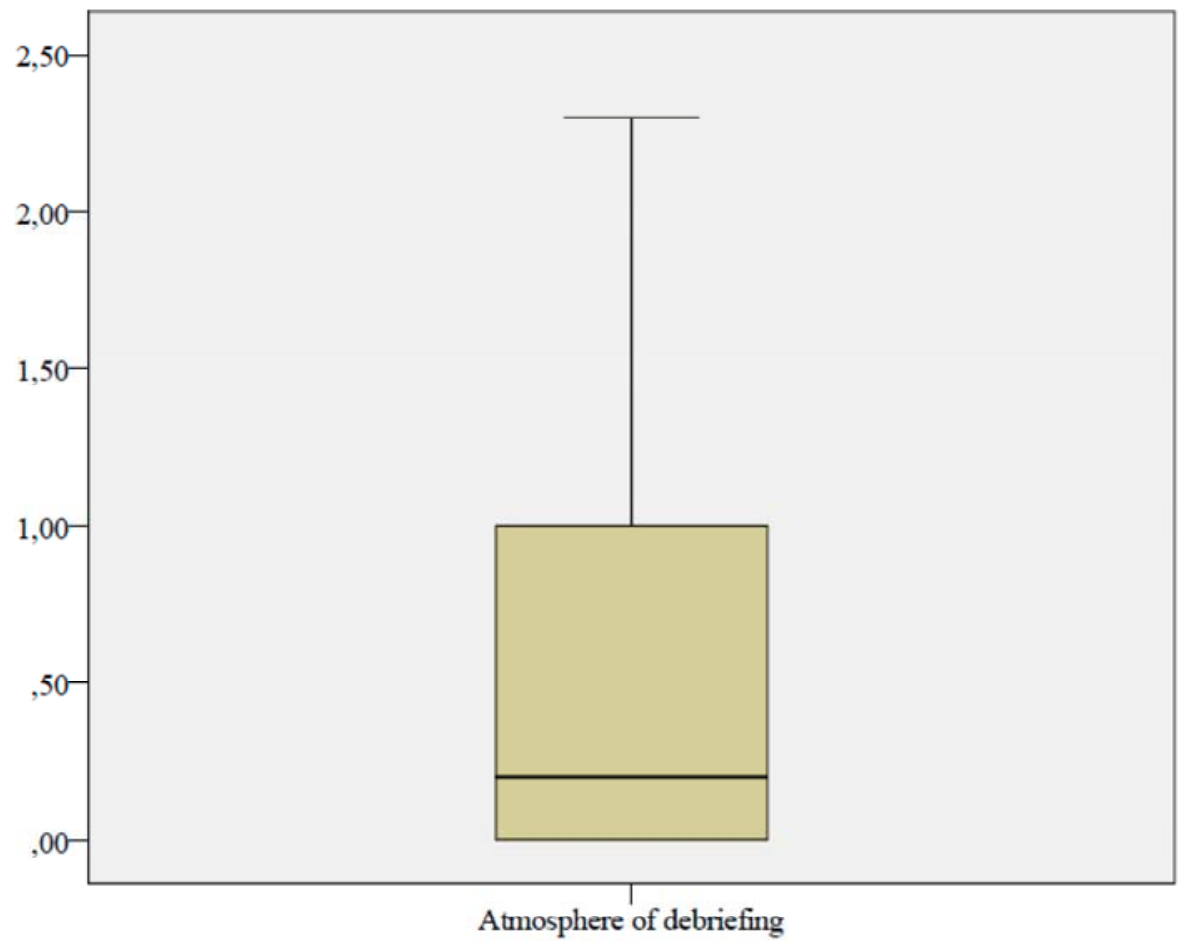

Fig. (5). Experiences of students in the nurse teacher education on the atmosphere of the debriefing.

Three students $(n=3)$ also found the debriefing personally touching and challenging.

“...For me, there was feedback waiting for me in the first group on my own behavior and everything said about me resonated with me but in the end I felt really good"

"Challenging yourself is a "challenge" but it's not oppressive!"

Three $(n=3)$ students brought up the challenge caused by the group size in having the same ideas come up repeatedly as presented by different students. Moreover, one student $(n=1)$ indicated having felt unease in the feedback discussion session.

"Difficult to come up with anything new to say when the group is so big"

"...everyone had to have something to say even when they did not necessarily have anything to say or when a fellow student has just said the same thing”,

"The situation was slightly uncomfortable. I don't even quite know why" 


\section{DISCUSSION}

Health care and health care training have introduced teaching methods from safety-critical fields (e.g., aviation and military training), where issues connected to safety have been taught for decades by using the simulation teaching method [13, 32]. The simulation teaching and learning method has become increasingly popular in health care and health care training during the previous decade, which is evinced by a clearly increased number of simulation research and literature on both national (e.g., [1, 23]) and international (e.g., [6-7, 36]) levels. In health care, medicine, and nursing science, emergency care and acute care have pioneered the use of simulation teaching and learning; the early-stage simulations particularly concentrated on practicing the management of clinical/technical skills. Today, simulations are used fairly extensively in the field of health care and its training by practicing different situations with patients and customers and other nursing and interaction situations. The goal of simulation exercises is to also increasingly pay attention to non-technical skills and simulation has been utilized to develop, for instance, communication, decision-making, leadership, and team work, and the learning results gained from these areas have primarily encouraged the use of the simulation method [5, $20]$.

As simulation learning is highly connected to experiential learning [24], this study highlighted the importance of experiencing a coherent simulation event from beginning to end, and at the same time, gain information of simulation pedagogy and backgrounds. Of the nurse-teacher student group, only 3 of the 17 had earlier experiences with simulation, which illustrates the need for embedding simulation as a topic into nurse teacher education. As a nurse-teacher education organization, the need for giving upto-date education to students is high, and therefore, the simulation is integrated into the curriculum of the Department of Nursing Science at the University of Eastern Finland [33].

Based on the current study results, the majority of the students reported that they were able to distinguish between the stages of the simulation after the event. All the students, however, did not actually use the simulation-specific concepts while describing the stages: preparation / planning for the simulation (including defining the goals), running the simulation, and debriefing. Instead, the students used more general terms, such as, "planning, action, evaluation", or more specific ones, "...ending the simulation, a round, where the actors describe the case and reveal their roles, watching at the cases (from monitor), going through positive issues, going through negative issues". This may give some development ideas for the next similar study module for nurse teacher students to emphasize the different stages and concepts more clearly. Naturally, based on one simulation event and previous theoretical introduction sessions only, the concepts may not be the most important issue to learn, but to obtain a picture of the whole event and be able to differentiate the stages using their own words is a good start. After all, the practices and related concepts are still evolving in simulation [34].

The results show that over two-thirds of students were confident in their own skills to plan a simulation education in a health care setting after the simulation event, as even they recognized the importance of future experiences and repetition. Similarly, two-thirds of students were confident that they could actually implement the simulation. As a nurse-teacher education organization, we have to be aware of the latest movements of nurse education, prepare our students to face reality, and give them "blocks" on which they can build when they enter their work life. Teacher education in general has been criticized for its detachment from "real" life in schools, when the novice teachers have not had sufficient skills when they encountered challenging or new situations after entering work life [35].

The majority of students agreed that the simulation event promoted their learning about the possibilities of simulation. Furthermore, the students described that their understanding towards versatility of learning methods, role of the teacher, and a safe group for learning increased. Obviously, the pedagogical skills and the long experience of a teacher, who led the simulation event, had a positive impact on the outcome. The instructor's role in simulation is very important, as, according to Reising et al. [36], the students may experience the simulation as being more stressful than the traditional roundtable group work. The instructor's role is also multi-sided, requiring a variety of skills; for example, in the stage of debriefing, the teacher has to be the information provider, role model, facilitator, assessor, planner, and resource developer [25]. The expertise of the teacher also was emphasized through students' open answers in this study, when they judged the debriefing environment as good, encouraging, and appropriate.

Congruent with the previous literature [37-39], the students experienced the stage of debriefing as a very important part of the simulation event. Interestingly, Dotger and Smith [39] concluded, based on their research on the effects of simulation on student teachers' identity, that reflection after the simulation event "shaped" the students" identity. Reflection actually raised some criticism about their individual professional skills. Some students in this study pointed out that either they felt a bit uncomfortable in the debriefing or felt that the group was too big to function properly. The simulation group, overall, was considered a safe, closed environment, which has also been emphasized in previous research (e.g., [7]). So far, however, there is no comprehensive information or agreement available for optimal group size in simulations. For example, Rezmer et al. [40] studied groups of two, three, and four students; they found no difference in students' experiences towards simulation and concluded that a group of four is quite small for a simulation. Obviously, the content of a simulation also influences the group size, as well as the resources of the education unit.

More studies are needed to validate the study findings, but preliminary implications for nurse teacher education, as well as for future research, can be driven. Results of this pilot study suggest that future nurse teachers urgently need simulation experience and coherent background knowledge from simulations. Nurse teacher educators in universities should acknowledge the students' own experiences of simulation and obtain feedback to develop the teaching module further. This study, for instance, brought out the importance of using correct concepts in teaching, which 
should also be one target of education. For example, using the concept "evaluation" instead of "debriefing" does not give the full description of the true meaning of debriefing, but may leave out the important contents and ways of critical reflection. Future research is needed within nurse-teacher education units to obtain new information about nurse teacher students' experiences towards simulation and possibly to conduct a comparative study design of different learning methods, as well as to develop the simulation education further.

\section{CONCLUSION}

As learning and teaching method, simulation enables nurse teacher students to practice safely situations corresponding with the reality of professions and expert positions in the field of health care. The role of teachers working in simulation learning events is multifaceted and important. This means that teachers must master simulation pedagogy and concepts dealing with it when the aim is to get fruitful and high-quality learning results from students. Therefore, it is important that nurse teacher students establish basic competence on the concepts and practices of simulation, as well as the pedagogy behind simulation learning events that can be utilized in their future work.

\section{CONFLICT OF INTEREST}

The authors confirm that this article content has no conflict of interest.

\section{ACKNOWLEDGEMENTS}

Declared none.

\section{REFERENCES}

[1] Salakari H. Simulaattorikoulutuksen hyödyt opiskelijoille, koulutettaville organisaatioille ja kouluttajille (The Benefits of Simulator Training to Students, Organisations in Training and Educators). In: Salakari H. Simulaattorikouluttajan käsikirja (Simulator Trainer's Manual) Eduskills Consulting. Hakapaino OY, Helsinki 2010; pp. 12-7.

[2] Berragan L. Simulation: an effective pedagogical approach for nursing? Nurse Educ Today 2011; 31(7): 660-3.

[3] Flanagan B, Nestel D, Joseph M. Making patient safety the focus: crisis resource management in the undergraduate curriculum. Med Educ 2004; 38(1): 56-66.

[4] Alinier G. Developing high-fidelity health care simulation scenarios: a guide for educators and professionals. Simul Gaming 2011; 42(1): 9-26.

[5] Lewis R, Strachan A, McKenzie-Smith M. Is high fidelity simulation the most effective method for the development of nontechnical skills in nursing? A review of the current evidence. Open Nurs J 2012; 6: 82-9.

[6] Wotton K, Davis J, Button D, Kelton M. Third-year undergraduate nursing students' perceptions of high-fidelity simulation. J Nurs Educ 2010; 49(11): 632-9.

[7] Hope A, Garside J, Prescott S. Rethinking theory and practice: preregistration student nurses experiences of simulation teaching and learning in the acquisition of clinical skills in preparation for practice. Nurse Educ Today 2011; 31(7): 711-5.

[8] Dillon PA, Noble KA, Kaplan L. Simulation as a means to foster collaborative interdisciplinary education. Nurs Educ Perspect 2009; 30(2): 87-90.

[9] Cato ML, Lasater K, Peeples AI. Nursing students' self-assessment of their simulation experiences. Nurs Educ Perspect 2009; 30(2): $105-8$

[10] Bambini D, Washburn J, Perkins R. Outcomes of clinical simulation for novice nursing students: communication, confidence, clinical judgment. Nurs Educ Perspect 2009; 30(2): 7982 .
[11] Brindley $P$, Reynolds S. Improving verbal communication in critical care medicine. J Crit Care 2011; 26(2): 155-9.

[12] Marshall S, Harrison J, Flanagan B. The teaching of a structured tool improves the clarity and content of interprofessional clinical communication. Qual Saf Health Care 2009; 18(2): 137-40.

[13] Rall M, Dieckmann P. Safety culture and crisis resource management in airway management: general principles to enhance patient safety in critical airway situations. Best Pract Res Clin Anaesthesiol 2005; 19(4): 539-57.

[14] Nagle BM, McHale JM, Alexander GA, French BM. Incorporating scenario-based simulation into a hospital nursing education program. J Contin Educ Nurs 2009; 40(1):18-25.

[15] Medley CF, Horne C. Using simulation technology for undergraduate nursing education. J Nurs Educ 2005; 44(1): 31-4.

[16] Schiavento M. Reevaluating simulation in nursing education: beyond the human patient simulator. J Nurs Educ 2009; 48(7): 38894.

[17] Cannon-Diehl MR. Simulation in healthcare and nursing: state of the science. Crit Care Nurs Q 2009; 32(2): 128-36.

[18] Wear D, Varley JD. Rituals of verification: the role of simulation in developing and evaluating empathic communication. Patient Educ Couns 2008; 71(2):153-6.

[19] Paskins Z, Peile E. Final year medical students' views on simulation-based teaching: a comparison with the best evidence medical education systematic review. Med Teach 2010; 32(7): 56977.

[20] Pearson E, McLafferty I. The use of simulation as a learning approach to non-technical skills awareness in final year student nurses. Nurse Educ Pract 2011; 11(6): 399-405.

[21] Walton J, Chute E, Ball L. Negotiating the role of the professional nurse: the pedagogy of simulation: a grounded theory study. J Prof Nurs 2011; 27: 299-310.

[22] Puolimatka T. Opetuksen kaksi lähestymistapaa. Realistinen lähestymistapa. In: The Theory of Teaching. From Constructivism to Realism Tammi. Vammalan kirjapaino Oy, Vammala 2002; pp. $15-20$.

[23] Pakkanen J, Stolt M, Salminen L. Patient simulation in learning nursing skills in nursing education - a literature review. J Nurs Sci 2012; 24: 163-74.

[24] Kolb DA. Experiential learning: experience as the source of learning and development. Englewood Cliffs, NJ: Prentice Hall 1984.

[25] Dieckmann P, Friis SM, Lippert A, Østergaard D. The art and science of debriefing in simulation: ideal and practice. Med Teach 2009; 31(7): e287-e94.

[26] Sinclair B, Ferguson K. Integrating simulated teaching/learning strategies in undergraduate nursing education. Int $\mathrm{J}$ Nurs Educ Scholarsh 2009; 6(1): Article 7.

[27] Pashler H, McDaniel M, Rohrer D, Bjork R. Learning styles. Concepts and evidence. Psychol Sci Public Interest 2009; 9(3): 105-19.

[28] Joyce B, Calhoun E, Hopkins D. Models of learning - Tools for teaching. $2^{\text {nd }}$ ed. Buckingham: Open University Press 2002.

[29] Dieckmann P, Gaba D, Rall M. Deepening the theoretical foundations of patient simulation as social practice. Simul Healthc 2007; 2(3): 183-93.

[30] Polit DF, Beck CT. Nursing research. Generating and assessing evidence for nursing practice (9th ed.). Philadelphia: Lippincott Williams \& Wilkins 2011

[31] Academy of Finland. Guidelines on research ethics. Retrieved 2013 May 23, from: http://www.aka.fi/Tiedostot/Tiedostot/Julkaisut/Suomen\%20Akate mian\%20eettiset\%20ohjeet\%202003.pdf

[32] Weinberg ER, Auerbach MA, Shah NB. The use of simulation for pediatric training and assessment. Curr Opin Pediatr 2009; 21(3): 282-7.

[33] Opinto-opas 2011-2012 (Study guide 2011-2012). Faculty of Health Science. Department of Nursing Science. University of Eastern Finland. Retrieved 2013 June 3, from: http://www.uef.fi/documents/1009628/1010099/opintoopas_hoitotiede_valmis_kartat.pdf/f0951e16-fe3f-46a0-90a41357ce0c662d

[34] Dreifuerst KT. The essentials of debriefing in simulation learning: a concept analysis. Nurs EducPerspect 2009; 30(2): 109-14.

[35] Sormunen M, Tossavainen K, Turunen H. Home-school collaboration in the view of fourth grade pupils, parents, teachers, 
and principals in the Finnish education system. School Community J 2011; 21(2): 185-211.

[36] Reising DL, Carr DE, Shea RA, King JM. Comparison of communication outcomes in traditional versus simulation strategies in nursing and medical students. Nurs Educ Perspect 2011; 32(5): 323-7.

[37] Arafeh JMR, Hansen SS, Nichols A. Debriefing in simulated-based learning. Facilitating a reflective discussion. J Perinat Neonat Nurs 2010; 24(4): 302-9.
[38] Chronister C, Brown D. Comparison of simulation debriefing methods. Clin Simulat Nurs 2012; 8(7): e281-e8.

[39] Dotger B, Smith M. Where is the line? - Negotiating simulated experiences to define teacher identity. New Educ 2009; 5: 161-180. Retrieved $2013 \quad$ May 23, from: http://www1.ccny.cuny.edu/prospective/education/theneweducator/ upload/4th-article-2.pdf

[40] Rezmer J, Begaz T, Treat R, Tews M. Impact of group size on the effectiveness of a resuscitation simulation curriculum for medical students. Teach Learn Med 2011; 23(3): 251-5.

(C) Saaranen et al.; Licensee Bentham Open.

This is an open access article licensed under the terms of the Creative Commons Attribution Non-Commercial License (http://creativecommons.org/licenses/by-nc/3.0/) which permits unrestricted, non-commercial use, distribution and reproduction in any medium, provided the work is properly cited. 